\title{
ANGKA KEJADIAN SUMBING BIBIR DI RSUP Prof. Dr. R. D. KANDOU MANADO PERIODE 2011-2013
}

\author{
${ }^{1}$ Andriani Supandi \\ ${ }^{2}$ Alwin Monoarfa \\ ${ }^{2}$ Mendy Hatibie Oley \\ ${ }^{1}$ Kandidat Skripsi Fakultas Kedokteran Universitas Sam Ratulangi Manado
${ }^{2}$ Bagian Bedah Fakultas Kedokteran Universitas Sam Ratulangi Manado
Email: andrianisupandi@yahoo.co.id
}

Abstract: Cleft lip is a gap defect in the upper lip tha tcan extend to the gums, jaw and palate that are formed in the first trimester of pregnancy because of the mesodermis is not formed in that area so the nasal and maxillary processes that have been fused into a broken back. Cleft lip is caused by genetic and environmental factors. This study aimed to obtain the incidence of cleft lip in Prof. Dr. R. D. Kandou General Hospital Manado for period 2011-2013. This was a descriptive retrospective study by using data of the Surgery Department and the Medical Record. The results showed that during the period 2011-2013, the most frequent cases were cleftlip and alveolar with cleft soft palate and hard palate (65.5\%). Unilateral cleft lip (66\%) was more common than bilateral cleft lip (34\%) and the localizations of defects were more common on the left (57\%). The number of male patients (67\%) were higher than the females (33\%). Most patients underwent surgery at the ages of 1-6 years (39\%). Most patients underwent Primary Lip Repair surgery (71\%) and the most frequent performed techniques was Triangular Variant (33\%).

Keywords: cleft lip, incidence

Abstrak: Sumbing bibir merupakan cacat berupa celah pada bibir atas yang dapat meneruskan diri sampai ke gusi, rahang dan langitan yang terbentuk pada trimester pertama kehamilan karena tidak terbentuknya mesoderm pada daerah tersebut sehingga prosesus nasalis dan maksilaris yang telah menyatu menjadi pecah kembali. Sumbing bibir disebabkan oleh faktor genetik dan lingkungan. Penelitian ini bertujuan untuk mengetahui angka kejadian sumbing bibir di RSUP Prof. Dr. R. D. Kandou Manado periode 2011-2013. Penelitian ini menggunakan metode deskriptif retrospektif melalui pengumpulan data di bagian Bedah dan bagian Rekam Medik RSUP Prof. Dr. R. D. Kandou Manado. Hasil penelitian menunjukkan bahwa selama periode 2011-2013 kasus tertinggi yang ditemukan adalah kasus sumbing bibir dan alveolus yang disertai dengan sumbing palatum lunak dan palatum keras (65,5\%). Sumbing bibir unilateral (66\%) lebih banyak ditemukan daripada sumbing bibir bilateral (34\%) dan lokalisasi defek lebih sering terjadi di sebelah kiri (57\%). Jumlah pasien lakilaki (67\%) lebih banyak ditemukan daripada perempuan (33\%). Sebagian besar pasien dilakukan operasi pada usia 1-6 tahun (39\%). Sebagian besar pasien dilakukan operasi Primary Lip Repair (71\%) dan tehnik operasi yang tersering ialah Triangular Variant (33\%).

Kata kunci: Angka kejadian, sumbing bibir

Sumbing bibir merupakan cacat berupa celah pada bibir atas yang dapat meneruskan diri sampai ke gusi, rahang dan langitan yang terbentuk pada trimester pertama kehamilan karena tak terbentuknya mesoderm pada daerah tersebut sehingga prosesus nasalis dan maksilaris yang telah menyatu menjadi pecah kembali. ${ }^{1}$

Deformitas ini dapat unilateral atau bilateral, inkomplet atau komplet. Ada kemungkinan yang terkena hanyalah bibir 
saja, atau dapat meluas sampai ke lubang hidung, atau mengenai tulang maksila dan gigi. Sumbing bibir dan palatum bisa terjadi secara terpisah atau bersamasama. $^{2,3}$

Ada 14 jenis cacat bawaan celah muka, sumbing bibir dan langitan adalah yang paling sering dijumpai, angka keterjadiannya kira-kira satu di antara 800 kelahiran. ${ }^{1}$ Insidens celah bibir (sumbing) dengan atau tanpa adanya celah pada palatum, kira-kira terdapat 1:600 kelahiran, insidens celah palatum saja sekitar 1:1.000 kelahiran. Insiden tertinggi kelainan ini terdapat pada orang Asia dan terendah pada orang kulit hita. ${ }^{4}$

Data internasional mencatat dalam periode 2002 sampai 2006, insiden sumbing bibir rata-rata terdapat 8 per 10.000 kelahiran di dunia. Tingkat kelahiran dengan sumbing bibir tertinggi adalah Jepang danterendahAfrika Selatan. ${ }^{5,6}$

Di Republik Ceko, ditemukan 2147 bayi dengan cacat sumbing yang ditemukan dari 1.471.789 kelahiran dalam periode tahun 1994 sampai dengan tahun 2008. Setiap tahun terdapat sekitar 170bayidengan sumbing bibirdan /atau langit-langit. Insiden keseluruhanadalah1 dari 600kelahiran hidup. Kira-kira kejadian sumbing bibir terdapat pada 1 dari 2648 kelahiran hidup, sumbing bibir dan langitan terdapat 1dari 1801 kelahiran hidup dan sumbing langitan terdapat 1dari 1505kelahiran. ${ }^{7}$

Pusat Pengendaliandan Pencegahan Penyakit (CDC) baru-baru ini memperkirakan bahwa setiap tahun 2.651 bayi di AmerikaSerikat yang lahir dengan bibir sumbing dan 4.437 bayi lahir dengan bibir sumbing dengan atau tanpa celah palate. $^{8}$ Di Indonesia penderita kelainan sumbing bibir di Indonesia bertambah ratarata 7.500 orang per tahun. ${ }^{9}$

Penyebab sumbing bibir yaitu faktor genetik yang termodifikasi oleh agen dari luar tubuh. ${ }^{10}$ Sebagian besar kasus sumbing bibir dapat dijelaskan dengan hipotesis multifaktor. Teori multifaktor yang diturunkan menyatakan bahwa gen-gen yang beresiko berinteraksi satu dengan lainnya dan dengan lingkungan, menyebabkan cacat pada perkembangan janin. Faktor lingkungan yang bisa menjadi kemungkinan penyebab kelainan sumbing bibir bisa meliputi ibu yang terpajan obat, defisiensi nutrisi, penyakit infeksi, radiasi, stress emosional, merokok, dan trauma pada masa kehamilan. ${ }^{4,11}$

Pengelolaan sumbing bibir merupakan pengelolaan multidisipliner. Program rehabilitasi yang menyeluruh untuk anak yang menderita sumbing bibir bisa memerlukan pengobatan khusus dalam kurun waktu bertahun-tahun, dari tim yang terdiri atas dokter ahli anak untuk mengontrol kesehatan bayi atau anak, ahli bedah plastik untuk melakukan tindakan operasi, ahli THT yang mungkin diperlukan bila terjadi gangguan pada telinga, dokter gigi anak, prostodontis, dan ortodontis yang akan mengawasi perkembangan rahang dan gigi, ahli terapi wicara yang mengawasi dan membimbing kemampuan bicara, ahli psikologi dan psikiater anak untuk menangani masalah psikologis yang timbul. ${ }^{1,4,12}$

Komplikasi yang bisa terjadi berupa infeksi, otitis media berulang dan ketulian. Jarang dijumpai kasus karies gigi yang berlebihan. Cacat wicara bisa ada atau menetap meskipun psenutupan palatum secara anatomik telah dilakukan dengan baik. $^{4}$

Berdasarkan uraian di atas, sumbing bibir merupakan salah satu masalah di bidang bedah plastik yang membutuhkan penanganan segera dan perhatian penting. Hal tersebut membuat penulis tertarik untuk melakukan penelitian tentang angka kejadian sumbing bibir di RSUP prof. Dr. R. D. Kandou Manado periode 2011 sampai 2013.

\section{METODE PENELITIAN}

Penelitian ini menggunakan metode deskriptif retrospektif melalui pengumpulan data di Bagian bedah dan Rekam Medik RSUP Prof. Dr. R. D. Kandou 
Manado untuk mengetahui angka kejadian sumbing bibir di RSUP Prof. Dr. R. D. Kandou Manado periode 2011-2013. Penelitian ini dilakukan pada bulan Januari-Februari 2014 di bagian Bedah dan bagian Rekam Medik RSUP Prof. Dr. R. D. Kandou Manado. Variabel yang diteliti ialah jumlah kasus sumbing bibir, jenis sumbing, jenis kelamin pasien sumbing bibir, jenis operasi yang dilakukan pada pasien sumbing bibir dan usia pasien sumbing bibir pada saat melakukan operasi. Subjek penelitian ini ialah semua pasien sumbing bibir di RSUP Prof. Dr. R. D. Kandou Manado periode 2011-2013.

\section{HASIL PENELITIAN DAN BAHASAN}

Selama periode 2011-2013 di RSUP Prof. Dr. R. D. Kandou Manado terdapat 142 kasus sumbing bibir. Sumbing bibir merupakan cacat berupa celah pada bibir atas yang dapat meneruskan diri sampai ke gusi, rahang dan langitan yang terbentuk pada trimester pertama kehamilan. ${ }^{1}$ Di Indonesia jumlah kasus sumbing bibir mencapai 7.500 orang per tahun. ${ }^{9}$ Hal ini menunjukkan kasus sumbing bibir merupakan masalah di kalangan masyarakat Indonesia.

Masalah yang ditimbulkan akibat cacat ini ialah masalah fungsi, estetik dan psikis, ketiganya saling berhubungan ${ }^{1}$, yang paling penting ialah mengenai asupan gisi penderita sumbing bibir, apabila terdapat celah pada bibir dan gusi maka penderita tidak bisa menyusui dengan baik, sehingga asupan nutrisi dapat terganggu. Selain itu juga masalah pada penampilan wajah dari pasien sumbing yang dapat mempengaruhi psikis penderita sumbing bibir tersebut dan pengaruhnya terhadap kehidupan sosial.

Tabel 1 menunjukkan bahwa dari 142 kasus sumbing bibir, paling banyak ditemukan kasus Sumbing bibir dan alveoulus disertai dengan sumbing palatum lunak dan palatum keras yaitu terdapat 93 kasus. Hal ini sesuai dengan penelitian yang dilakukan di Faculty of Medicine University of Tartu, Estonia pada tahun 2012 yang menemukan lebih banyak Sumbing bibir yang disertai dengan palatum daripada sumbing bibir tanpa disertai palatum. ${ }^{13}$

Tabel 1. Distribusi Jenis Sumbing Bibir

\begin{tabular}{ccc}
\hline Jenis Sumbing & Jumlah & $\%$ \\
\hline Sumbing Bibir & 28 & 19,7 \\
Sumbing Bibir \& Alveolus & 18 & 12,7 \\
Sumbing Bibir \& Alveolus dengan Sumbing Palatum Lunak & 93 & 65,5 \\
\& Palatum Keras & 1 & 0,7 \\
Sumbing Bibir \& Alveolus dengan Sumbing Palatum Lunak & 2 & 1,4 \\
Sumbing Bibir dengan Sumbing Palatum Lunak & 142 & 100 \\
Total & & \\
\hline
\end{tabular}

Pada Tabel 2 dapat dilihat bahwa terdapat lebih banyak kasus sumbing bibir unilateral daripada sumbing bibir bilateral. Ditemukan 48 kasus sumbing bibir bilateral dan 94 kasus sumbing bibir unilateral dengan unilateral (kanan) sebanyak 40 kasus dan unilateral (kiri) sebanyak 54 kasus, di sini dapat dilihat bahwa lokalisasi defeknya lebih sering terjadi pada sisi kiri. Hal tersebut sama dengan hasil penelitian yang dilakukan oleh Teuku Ahmad di Fakultas Kedokteran Universitas Indonesia pada tahun 2012 yang menyatakan bahwa lokalisasi defek sumbing bibir lebih sering terjadi pada sisi kiri. $^{14}$ Hal tersebut dikarenakan perkembangan sisi kiri lebih lambat daripada sisi kanan. 
Tabel 2. Distribusi Sumbing Bibir Menurut Lokalisasi Defek

\begin{tabular}{ccccc}
\hline Jenis Sumbing & \multicolumn{3}{c}{ Distribusi Sumbing } & Total \\
\cline { 2 - 4 } & $\begin{array}{c}\text { Unilateral } \\
\text { (Kanan) }\end{array}$ & $\begin{array}{c}\text { Unilateral } \\
\text { (Kiri) }\end{array}$ & Bilateral & \\
\hline Sumbing Bibir & 13 & 12 & 3 & 28 \\
Sumbing Bibir \& Alveolus & 5 & 11 & 2 & 18 \\
$\begin{array}{c}\text { Sumbing Bibir \& Alveolus dengan Sumbing } \\
\text { Palatum Lunak \& Palatum Keras }\end{array}$ & 21 & 30 & 42 & 93 \\
Sumbing Bibir \& Alveolus dengan Sumbing & 1 & 0 & 0 & 1 \\
$\quad$ Palatum Lunak & & 1 & 1 & 2 \\
Sumbing Bibir dengan Sumbing Palatum Lunak \\
$\quad$ Total & 0 & 50 & 48 & 142 \\
\hline
\end{tabular}

Tabel 3 merupakan distribusi sumbing bibir berdasarkan jenis kelamin. Pada tabel 3 menunjukkan bahwa dari 142 kasus sumbing bibir di RSUP Prof. Dr. R. D. Kandou Manado selama periode 2011 2013 terdapat 67\% pasien laki-laki yaitu sebanyak 95 pasien dan hanya ditemukan 33\% pada perempuan yaitu 45 pasien. Hal ini jelas menunjukkan bahwa bibir sumbing lebih banyak ditemukan pada pasien laki-laki daripada perempuan. Hal tersebut sesuai dengan kepustakaan yang menyatakan bahwa sumbing bibir lebih sering terjadi pada laki-laki daripada perempuan. ${ }^{4}$ Selain itu juga penelitian yang dilakukan oleh Triin Jagomagi, Marianne Soots dan Mare Saag pada tahun 2012 menyimpulkan bahwa sumbing bibir lebih sering terjadi pada laki-laki daripada perempuan.

Tabel 3. Distribusi Sumbing Bibir Menurut Jenis Kelamin

\begin{tabular}{ccc}
\hline Jenis Kelamin & Jumlah & $\%$ \\
\hline Laki-laki & 95 & 67 \\
Perempuan & 47 & 33 \\
Total & 142 & 100 \\
\hline
\end{tabular}

Hasil tersebut juga sesuai dengan penelitian yang dilakukan oleh FoghAndersen (1942) dan dikonfirmasi oleh penelitian lain yang dilakukan oleh Fraser dan Calnan (1961) ; Ingalls dan Coworkers (1964) yang menyatakan bahwa sumbing bibir unilateral sisi kiri lebih sering terjadi dibandingkan jenis sumbing bibir lainnya serta sumbing bibir lebih sering terjadi pada laki-laki daripada perempuan. ${ }^{15}$

Pada tabel 4 menunjukkan bahwa sebagian besar pasien melakukan operasi pada usia kanak-kanak dengan usia terbanyak pada uisa 1-6 tahun yaitu sebanyak 39\% dari kasus. Dapat dikatakan bahwa sebagian besar pasien sudah memiliki kesadaran untuk mengobati masalah sumbing bibir sejak dini. Tindakan operasi bibir sumbing sebaiknya dilakukan sedini mungkin dengan mengacu kepada rule of tens, yaitu berat minimal 10 pounds, usia 10 minggu, hb minimal 10 gr/dl dan leukosit di bawah 10.000. ${ }^{4}$ Dari data yang ada juga ditemukan pasien yang melakukan operasi sumbing bibir di usia remaja hal ini berkaitan karena penanganan sumbing bibir merupakan penanganan multidisipliner yang memerlukan waktu bertahun-tahun. Operasi lanjutan dilakukan untuk penanganan terhadap kerusakankerusakan lainnya seperti perbaikan bentuk hidung dan pembentukan tulang wajah.,4 
Perbaikan secara bedah melibatkan beberapa prosedur primer dan sekunder yang prosedur pembedahannya dan waktu pelaksanaannya bervariasi tergantung dari tingkat keparahannya dan keputusan dari dokter bedah. ${ }^{11}$

Tabel 4. Distribusi Usia Pasien Sumbing Bibir Pada Waktu Dilakukan Operasi

\begin{tabular}{ccc}
\hline Usia (Tahun) & Jumlah & $\%$ \\
\hline$<1$ & 20 & 14 \\
$1-6$ & 55 & 39 \\
$7-12$ & 21 & 15 \\
$13-18$ & 12 & 8 \\
$>18$ & 34 & 24 \\
Total & 142 & 100 \\
\hline
\end{tabular}

Pada tabel 5 menujukkan jenis operasi yang dilakukan pada pasien sumbing bibir. Paling banyak ditemukan pasien sumbing bibir yang melakukan operasi Primary Lip Unilateral Repair yaitu sebanyak 75 operasi, sesuai dengan tabel 3 dan gambar 13 yang menyatakan paling banyak ditemukan pasien sumbing bibir unilateral. Selain itu terdapat 26 operasi Primary Lip Bilateral Repair, 37 operasi Lip Revision dan sisanya melakukan operasi Fistula repair.

Dapat diketahui bahwa terdapat 101 pasien sumbing bibir unilateral maupun sumbing bibir bilateral yang melakukan operasi Primary Lip Repair, hal ini mencakup sebagian besar dari 142 operasi yang dilakukan. Primary Lip Repair adalah operasi sumbing bibir yang pertama kali dilakukan kepada pasien sumbing bibir, pasien sebelumnya belum pernah melakukan operasi sumbing jenis apapun. Sesuai dengan tabel 5 dan gambar 5 yang menyatakan bahwa sebagian besar pasien yang melakukan operasi sumbing bibir adalah anak-anak, karena operasi sumbing bibir pertama kali sudah boleh dilakukan sejak usia tiga bulan, pada saat itu struktur bibir sudah berkembang dan terdapat jaringan yang lebih besar untuk dioperasi. $^{15}$ Tujuan dilakukannya operasi perbaikan bibir primer atau pertama adalah untuk menutup celah bibir sehingga dapat membantu mendekatkan jarak celah gusi agar pasien bisa menyusui secara normal dan asupan nutrisi pada pasien bisa tetap terjaga, selain itu juga untuk mendapatkan penampilan bentuk bibir dan wajah yang lebih baik. ${ }^{1,11}$ Dengan tujuan tersebut maka operasi sumbing bibir harus dilakukan sedini mungkin.

Tabel 5. Distribusi Jenis Operasi Sumbing Bibir

\begin{tabular}{ccc}
\hline Jenis Operasi & Jumlah & $\%$ \\
\hline Primary Lip Biateral Repair & 26 & 18 \\
Lip Revision & 37 & 26 \\
Primary Lip Unilateral Repair & 75 & 53 \\
Fistula Repair & 4 & 3 \\
Total & 142 & 100 \\
\hline
\end{tabular}

Tabel 6 menyatakan distribusi jenis repair sumbing bibir, yang dimaksud di sini adalah teknik operasi yang dilakukan terhadap pasien sumbing bibir. Dapat 
dilihat pada Tabel 6 bahwa jenis repair sumbing bibir yang paling sering digunakan adalah jenis Triangular Variant yaitu sebanyak 47 operasi. Triangular Variant adalah salah satu jenis repair sumbing bibir yang dilakukan pada operasi sumbing bibir unilateral. Data yang ada pada tabel 6 juga menyebutkan bahwa terdapat 32 jenis repair RotationAdvancement Variant yang juga merupakan jenis repair sumbing bibir unilateral.

Triangular Variant dan RotationAdvancement Variant merupakan dua teknik operasi yang sering digunakan. Teknik Triangular Variant dikembangkan oleh Tennison et al. dengan menggunakan flap triangular dari sisi lateral, dimasukkan ke sudut di sisi medial dari celah tepat diatas batas vermillion, melintasi collum philtral sampai ke puncak cupid. Triangle ini menambah panjang di sisi terpendek dari bibir. Teknik ini menghasilkan panjang bibir yang baik tetapi jaringan parut yang terbentuk tidak terlihat alami. ${ }^{16}$

Teknik Rotation-Advancement Variant pertama kali diperkenalkan oleh seorang ahli bedah Millard (1960) Kelebihan teknik ini ialah penempatan jahitan sepanjang garis filtrum dan dasar hidung sehingga terlihat lebih natural Parut ditempatkan tinggi di bawah dasar hidung dan sepanjang garis filtrum sehingga memperkecil jarak penglihatan bekas jahitan. ${ }^{17}$

Selain itu juga terdapat 21 operasi yang menggunakan jenis repair Forked Flap dan 13 Straight Line yang merupakan jenis repair yang dilakukan pada operasi sumbing bibir bilateral. Forked flap merupakan cara yang paling umum digunakan untuk penutupan celah komplit, keuntungan teknik ini adalah berkurangnya insiden terhadap fistula posterior. Straight Line digunakan untuk penutupan celah bibir bilateral komplit dengan prolabium yang panjang. $^{18}$ Terdapat jenis repair lainnya, maksud dari jenis repair sumbing bibir lainnya di sini adalah jenis repair sumbing bibir selain yang disebutkan di atas, jenis repair sumbing bibir ini lebih kepada perbaikan bentuk bibir atau perbaikan luka (scar), termasuk juga di dalamnya perbaikan bentuk hidung.

Tabel 6. Distribusi Jenis Repair Sumbing Bibir

\begin{tabular}{ccc}
\hline Jenis Repair & Jumlah & $\%$ \\
\hline Forked Flap & 21 & 15 \\
Straight Line & 13 & 9 \\
Rotation-Advancement Variant & 32 & 23 \\
Triangular Variant & 47 & 33 \\
Jenis Lainnya & 29 & 20 \\
Total & 142 & 100 \\
\hline
\end{tabular}

\section{UCAPAN TERIMA KASIH}

Ucapan terima kasih ditujukan kepada semua pihak baik secara langsung maupun tidak langsung telah menumbuhkan ide dan gagasan pada penulis.

\section{DAFTAR PUSTAKA}

1. Bisono. Sumbing bibir/langitan. Dalam: Reksoprodjo S, editor. Kumpulan kuliah ilmu bedah.
Tanggerang: Binarupa Aksara. Hal 393-6.

2. Underwood JCE. Patologi umum dan sistematik. EGC: 1994;1(2):112.

3. Schwartz. Bedah kepala dan leher. Dalam: Chandranata L, editor. Intisari prinsip-prinsip ilmu bedah. Ed ke-6. Jakarta: EGC; 2000. Hal 688.

4. Nelson. Celah bibir dan palatum. Dalam: Wahab AS, editor. Ilmu kesehatan anak. Jakarta: EGC; 2000;2(15):1282. 
5. Division of Plastic Surgery. Department of Surgery, Scott \& White Healthcare, Texas A\&M Health Science Center College of Medicine. USA.

6. Tanaka SA, Mahabir RC, Jupiter DC, Menezes JM. Updating the epidemiology of cleft lip with or without cleft palate. March 2012;129(3):511-18.

7. Urbanova $\mathbf{W}$, Kotova $\mathbf{M}$, Vankova Z. The Insidence of cleft lip and palate in the Czech Republic in 19942008. Hongkong:

Oct 2004;10(5):3316.

8. Parker SE, Mai CT, Canfield MA, Rickard R, Wang Y, Meyer RE, et al.Updated national birth prevalence estimates for selected birth defects in the United States, 2004-2006. 2010;88(12):1008-16.

9. Kembaren L. Penderita bibir sumbing tambah 7500 per tahun. Jurnal Nasional. Kuta: Nov 2012. Hal 11.

10. Diaz Casado GH, Diaz Gravalos GJ. Orofacial closure defects: cleft lip and palate. A literature review. Semergen: Jul-Aug;39(5):267-71.

11. Widowati GT. Distribusi frekuensi celah bibir dan langitan di RSAB harapan kita tahun 1996 dan 1999 [SKRIPSI]. Universitas Indonesia: 2008.
12. Sjamsuhidayat $\mathbf{R}$, de Jong W. Buku ajar ilmu bedah. Ed ke-2. Jakarta: EGC; 2005. Hal 344-5.

13. Jagomagi $\mathbf{T}$, Soots $\mathbf{M}$, Saag $\mathbf{M}$. Epidemiologic factors causing cleft lip and palate and their regularities of occurence in Estonia. Stomalogija: 2010;12:105-8.

14. Arbi TA. Evaluasi labioplasty cronin dan palatoplasty push back pada celah bibir dan langitan unilateral. Universitas Indonesia:2012.

15. Converse JM, Hogan VM, McCarthy JG. Cleft lip and palate introduction. Converse JM. Reconstructive plastic surgey. United States: W. B. Saunders Company; 1997;4(2):1938.

16. Nasution F, Masitah F, Ilvira MN, Gunawan IB, Yuliana N, Radiana AP, dkk. Cleft lip (Labioschisis). Sebagai bahan ajar di Fakultas kedokteran. Universitas Muhammadiyah Sumatra Utara: 20122013.

17. Gurusinga DC. Metode millard sebagai salah satu teknik penutupan celah bibir [SKRIPSI]. Universitas Sumatra Utara: 2005.

18. Haryuti S. Teknik operasi celah bibir dan langit-langit yang digunakan di sulawesi selatan pada tahun 20102013 [SKRIPSI]. Universitas Hasanuddin: 2013. 